\title{
Effects of Fermented Beverage in Subjects with Metabolic Syndrome
}

\author{
Min-Ju Kim', Jung-In Kim², Chung-Ho Ryư ${ }^{3}$, and Min-Jung Kang ${ }^{1}$ \\ ${ }^{1}$ Bio-Food Research Center, Hurom Co., Ltd., Gyeongnam 50969, Korea \\ ${ }^{2}$ Institute of Digital Anti-Aging Healthcare, Inje University, Gyeongnam 50834, Korea \\ ${ }^{3}$ Department of Agriculture Chemistry and Food Science and Technology, Institute of Agriculture and Life Science, \\ Gyeongsang National University, Gyeongnam 52828, Korea
}

\begin{abstract}
This study investigated the effects of fermented beverage, kale/apple juice containing $5 \%$ vinegar in subjects with metabolic syndrome. Subjects were randomly assigned to receive $250 \mathrm{~mL}$ fermented beverage or water containing fructose, glucose, and sucrose twice daily for 10 weeks. Consumption of the fermented beverage significantly decreased plasma triglyceride, thiobarbituric acid reactive substances (TBARS), tumor necrosis factor (TNF)- $\alpha$, and high sensitivity C-reactive protein (hs-CRP) levels compared to baseline values $(P<0.05)$. Furthermore, consumption of the fermented beverage significantly decreased homeostasis model assessment for insulin resistance (HOMA-IR) values and atherogenic indexes compared with baseline values $(P<0.05)$. In the control group, plasma triglyceride, TBARS, TNF- $\alpha$, and hs-CRP levels, atherogenic indexes, and HOMA-IR values did not significantly differ pre- and post-treatment. The fermented beverage inhibited the activities of $\alpha$-glucosidase and pancreatic lipase in vitro, therefore could be helpful in alleviating metabolic syndrome in subjects with metabolic syndrome.
\end{abstract}

Keywords: dyslipidemia, fermented beverage, insulin resistance, metabolic syndrome, vinegar

\section{INTRODUCTION}

Metabolic syndrome is a combination of disorders, including abdominal obesity, hypertension, hyperglycemia, insulin resistance, and dyslipidemia (Ando and Fujita, 2009; Abbasian et al., 2018). According to the National Health and Nutrition Survey, $16.3 \%$ of people aged 20 years and older are highly susceptible to metabolic syndrome. In the 2014 Korea National Health and Nutrition Examination Survey, $20 \%$ of adults were diagnosed with metabolic syndrome. Metabolic syndrome is a key risk factor for cardiovascular disease (CVD) and diabetes mellitus (Mottillo et al., 2010; Dragsbæk et al., 2016), and is associated with a 2.35-fold increase in risk of CVD and a 2.40-fold increase in risk of CVD mortality (Mottillo et al., 2010). In addition, elderly women with metabolic syndrome have 6.0- and 1.7-fold increased risks of type 2 diabetes and CVD, respectively (Dragsbæk et al., 2016). Thus, control of metabolic syndrome is important for prevention of CVD and type 2 diabetes.

Vinegar is produced by fermentation of fruit, vegetables, or grains by yeast and acetic acid bacteria. Traditionally, vinegar has been consumed as a food condiment or a preservative, however, vinegar has also recently been used as a food ingredient because of its functional properties. It has been known for centuries that vinegar has health benefits due to its antioxidant (Bouazza et al., 2016; Halima et al., 2018), antiobesity (Kondo et al., 2009; Halima et al., 2018), antidiabetic (Petsiou et al., 2014; Halima et al., 2016), anticancer (Samad et al., 2016), antimicrobial (Samad et al., 2016), and hypolipidemic (Kondo et al., 2009; Halima et al., 2016) properties.

Several studies have suggested that vinegars and organic acids have beneficial effects in improving insulin resistance (Johnston et al., 2009; Santos et al., 2019), obesity (Kondo et al., 2009), and hyperlipidemia. Johnston et al. (2009) reported that consumption of vinegar improved insulin sensitivity in subjects with insulin resistance and type 2 diabetes. Furthermore, vinegar was reported to improve glycemic and lipid profiles of subjects with type 2 diabetes and dyslipidemia. Vinegar intake improved blood glucose in humans by inhibiting $\alpha$-amylase activ- 
ity and enhancing glucose uptake (Santos et al., 2019).

Currently, many beverage products containing vinegar are consumed in Korea and many studies have been published on the physiological activity of vinegar. However, few clinical trials have reported the effects of beverages containing vinegar on metabolic syndrome. Therefore, this study investigated the effects of fermented beverage in subjects with metabolic syndrome.

\section{MATERIALS AND METHODS}

\section{Reagents}

Kale and apple were purchased from a market in Gimhae, Korea. Glucose, triglyceride, total cholesterol, high-density lipoprotein (HDL)-cholesterol, low-density lipoprotein (LDL)-cholesterol, alanine aminotransferase (ALT), and aspartate aminotransferase (AST) assay kits were purchased from Asan Co. (Seoul, Korea). Insulin, adiponectin, tumor necrosis factor (TNF)- $\alpha$, and high sensitivity C-reactive protein (hs-CRP) assay kits were purchased from Mercodia AB (Uppsala, Sweden). Acarbose and Orlistat were acquired from Bayer Korea (Seoul, Korea) and Roche Korea (Seoul, Korea), respectively. Other reagent grade chemicals were purchased from SigmaAldrich Co. (St. Louis, MO, USA).

\section{Preparation of fermented beverage}

Blackberry juice, carrot juice, and kale juice were prepared using a low-speed masticating juicer (HH-SBF11, Hurom Co., Ltd., Gimhae, Korea) and mixed at a ratio of 16:3:1 to prepare the blackberry/carrot/kale (BCK) juice. An alcoholic fermentation product of the BCK juice was created using Saccharomyces cerevisiae \#7013 and the alcohol fermentation product was fermented using Acetobacter pasteurianus KCTC 13188BP to produce the BCK vinegar. The acidity of $\mathrm{BCK}$ vinegar was $7.0 \pm 0.1 \%$. The kale juice and apple juice were prepared using a low-speed masticating juicer and mixed at a ratio of 45:55 to prepare the kale/apple juice. The fermented beverage was prepared by mixing kale/apple juice with $5 \% \mathrm{BCK}$ vinegar.

\section{Determination of total acidity, $\mathrm{pH}$, and organic acids contents}

Total acidity of the kale/apple juice and fermented beverage was measured by titrating $100 \mathrm{~mL}$ of 5 -fold diluted juice to $\mathrm{pH} 8.3$ with standardized $0.1 \mathrm{~N} \mathrm{NaOH}$. The total acidity was expressed as a percentage of citric acid per $100 \mathrm{~mL}$ of the juice and beverage. The $\mathrm{pH}$ of the kale/apple juice and fermented beverage was determined using a pH meter (AG 8603, Mettler-Toledo GmbH, Schwerzenbach, Switzerland) at $25 \pm 1^{\circ} \mathrm{C}$. Organic acid contents of the kale/apple juice and fermented beverage were determined using high-performance liquid chromatography
(Shimadzu Corporation, Kyoto, Japan).

Determination of total polyphenol and flavonoid contents One milliliter of kale/apple juice or fermented beverage were added to $4 \mathrm{~mL}$ of $100 \%$ methanol and incubated for $2 \mathrm{~h}$ at room temperature. The supernatant was collected after centrifuging the solution at $850 \mathrm{~g}$ and $4^{\circ} \mathrm{C}$ for 20 min.

The total polyphenol content was measured by the method developed by Folin and Denis (1912). Briefly, 400 $\mu \mathrm{L}$ of the supernatant was mixed with $200 \mu \mathrm{L}$ of $50 \%$ Folin-Ciocalteu reagent, and incubated for $3 \mathrm{~min}$. After addition of $2 \% \mathrm{Na}_{2} \mathrm{CO}_{3}(200 \mu \mathrm{L})$, the mixture was incubated for $60 \mathrm{~min}$ and the absorbance was measured at $750 \mathrm{~nm}$. The total polyphenol content was quantified using tannic acid as a standard. Total polyphenol content was expressed as milligrams of tannic acid equivalents (TAE) per $100 \mathrm{~mL}$ juice and beverage.

Total flavonoid content was determined using the method described by Zhishen with modification (1999). Briefly, $400 \mu \mathrm{L}$ of the supernatant was mixed with 300 $\mu \mathrm{L}$ of $5 \% \mathrm{NaNO}_{2}$. After $5 \mathrm{~min}, 300 \mu \mathrm{L}$ of $1 \% \mathrm{AlCl}_{3}$ was added, and the mixture was incubated for $5 \mathrm{~min}$. Two hundred microliters of $1 \mathrm{M} \mathrm{NaOH}$ and $70 \mu \mathrm{L}$ of deionized water were added sequentially. The absorbance of the mixture was measured at $510 \mathrm{~nm}$ using a spectrophotometer, and quantified using quercetin as a standard. Total flavonoid content was expressed as milligrams of quercetin equivalents $(\mathrm{QE})$ per $100 \mathrm{~mL}$ juice and beverage.

\section{Inhibition assay for $\alpha$-glucosidase and pancreatic lipase in vitro}

The kale/apple juice and fermented beverage were centrifuged at $850 \mathrm{~g}$ for $10 \mathrm{~min}$, following which the supernatants were used in enzyme inhibition assays.

Yeast $\alpha$-glucosidase inhibitory activity was measured according to the method described by Watanabe et al. (1997). Yeast $\alpha$-glucosidase (0.7 U) dissolved in $100 \mathrm{mM}$ phosphate buffer ( $\mathrm{pH} 7.0$ ) containing $2 \mathrm{mg} / \mathrm{mL}$ bovine serum albumin, and $0.2 \mathrm{mg} / \mathrm{mL} \mathrm{NaN}_{3}$ and $5 \mathrm{mM} p$-nitrophenyl- $\alpha$-D-glucopyranoside in the same buffer ( $\mathrm{pH}$ 7.0) were used as the enzyme and substrate solutions, respectively. Then, $50 \mu \mathrm{L}$ of the enzyme solution and $10 \mu \mathrm{L}$ of the test sample were mixed and the absorbance was measured at $405 \mathrm{~nm}$ using a microplate reader (Model 550, Bio-Rad Laboratories, Inc., Hercules, CA, USA). After incubation at room temperature for $5 \mathrm{~min}, 50 \mu \mathrm{L}$ of the substrate solution was added and the solution was incubated for an additional $5 \mathrm{~min}$. The increase in absorbance from time 0 was measured, and inhibitory activity was calculated as a percentage of the blank control. Acarbose $(5 \mathrm{mg} / \mathrm{mL})$ was used as a positive control.

Inhibitory activity against pancreatic lipase was deter- 
mined by the method described by Arai et al. (1999) using 4-methylumbelifery oleate as a substrate. Pancreatic lipase $(0.5 \mathrm{U})$ was dissolved in Mclvane buffer $(0.1 \mathrm{M}$ citrate- $\mathrm{Na}_{2} \mathrm{HPO}_{4}, \mathrm{pH}$ 7.4). The reaction mixture consisted of $20 \mu \mathrm{L}$ buffer, $25 \mu \mathrm{L}$ pancreatic lipase, $5 \mu \mathrm{L}$ of sample solution, and $50 \mu \mathrm{L} 4-\mathrm{MU}$ oleate $(0.1 \mathrm{mM})$. After incubation of the mixture at $37^{\circ} \mathrm{C}$ for $10 \mathrm{~min}$, the amount of 4-MU released by the lipase was determined using a fluorescence multi-detection reader (Bio-Tek Instruments, Inc., Winooski, VT, USA) at an excitation wavelength of $320 \mathrm{~nm}$ and an emission wavelength of $450 \mathrm{~nm}$. Orlistat $(10 \mathrm{mg} / \mathrm{mL})$ was used as a positive control.

\section{Clinical trials}

Subjects and study design: Twenty-four subjects (Gimhae, Korea) were recruited through announcements. Inclusion criteria included meeting at least two of the criteria for metabolic syndrome defined by the National Cholesterol Education Program-Adult Treatment Panel III (NCEPATP III) (2002). The criteria included waist circumference of $>40$ inches for men or $>35$ inches for women; systolic blood pressure (SBP) $>130 \mathrm{mmHg}$ or diastolic blood pressure (DBP) $>85 \mathrm{mmHg}$; fasting blood glucose levels $>100 \mathrm{mg} / \mathrm{dL}$; triglyceride levels $>150 \mathrm{mg} / \mathrm{dL}$; HDLcholesterol levels $<40 \mathrm{mg} / \mathrm{dL}$ for men or $<50 \mathrm{mg} / \mathrm{dL}$ for women. Exclusion criteria included liver disease, renal disease, gastrointestinal disease, inflammatory disease, cancer, pregnancy, breast-feeding, or any other serious disorder requiring regular medical treatment.

This study was randomized, double-blinded, and placebo controlled. Subjects (21 men and 3 women; $41.4 \pm 9.0$ years) to receive either $250 \mathrm{~mL}$ of fermented beverage or water containing fructose $(47.22 \mathrm{mg} / \mathrm{mL})$, glucose $(16.85$ $\mathrm{mg} / \mathrm{mL})$, and sucrose $(0.50 \mathrm{mg} / \mathrm{mL})$ twice daily for a 10 week treatment period. Anthropometric and biochemical assessments were performed at baseline and after the treatment period. All subjects were asked to maintain their habitual diet and lifestyle during the treatment period. Compliance was monitored by questioning the subjects every week. Informed consent was obtained from all subjects prior to the study. The study protocol was approved by the Korean Public Institutional Review Board (No. P01-201711-11-003).

Anthropometric measurements: Body weight and height of the subjects were measured, and body mass index (BMI) was calculated as body weight in $\mathrm{kg}$ divided by height in $\mathrm{m}^{2}$. Body fat content was measured with a bioimpendance analyzer (HBF-300, Omron Co., Kyoto, Japan). Waist circumference was measured at the midpoint between the lower rib margin and the iliac crest with measuring tape. Blood pressure was measured by using a mercury sphygmomanometer (Baumanometer, WA Baum Co., Inc., Copiague, NY, USA) while subjects were sitting after $5 \mathrm{~min}$ of rest.
Blood analysis: After an overnight fasting, blood samples were drawn from the antecubital vein and centrifuged at $3,000 \mathrm{~g}$ for $15 \mathrm{~min}$. Plasma glucose, triglyceride, total cholesterol, HDL-cholesterol, and LDL-cholesterol levels were measured enzymatically using commercial assay kits (Asan Co.). Plasma ALT and AST activities were determined enzymatically using assay kits. Plasma insulin, adiponectin, and TNF- $\alpha$ levels were measured using enzymelinked immunosorbent assay kits. The homeostasis model assessment for insulin resistance (HOMA-IR) was calculated by dividing the product of insulin $(\mu \mathrm{U} / \mathrm{mL})$ and glucose $(\mathrm{mmol} / \mathrm{L})$ by 22.5 . Atherogenic index was calculated as triglyceride/HDL-cholesterol.

Plasma lipid peroxidation was determined by measuring production of thiobarbituric acid reactive substances (TBARS) according to the method described by Ohkawa et al. (1979). Briefly, plasma was mixed with a solution of $15 \%$ trichloroacetic acid, $0.4 \%$ thiobarbituric acid, and $2.5 \% \mathrm{HCl}$, and the mixture was heated at $100^{\circ} \mathrm{C}$ for $45 \mathrm{~min}$. And then the reaction mixture was cooled on ice and centrifuged at $1,500 \mathrm{~g}$ for $15 \mathrm{~min}$. The absorbance of the supernatant was measured at $532 \mathrm{~nm}$ and the results were expressed as nmol of malondialdehyde/ $\mathrm{mL}$. Plasma glutathione (GSH) levels were measured according to the method described by Ellman (1959). Briefly, plasma was incubated with $10 \mathrm{mM}$ 5,5-dithiobis-2-nitrobenzonic acid in $0.1 \mathrm{M}$ phosphate buffer ( $\mathrm{pH} \mathrm{8.0)}$ for $15 \mathrm{~min}$ and the absorbance was measured at $534 \mathrm{~nm}$. The results were expressed as $\mathrm{nmol} / \mathrm{mg}$ protein.

\section{Statistical analysis}

All data were expressed as mean \pm standard deviation (SD). All statistical analysis were performed using the SPSS program (ver. 9.2, SAS Institute Inc., Cary, NC, USA). The significance of differences between mean values of kale/apple juice and fermented beverages were evaluated by Student's $t$-tests. Differences among groups were analyzed by one-way analysis of variance (ANOVA) followed by Tukey's post-hoc test. The significance of mean comparisons between baseline and after 10 weeks of consumption of fermented beverages were tested by paired $t$-test. Significance was defined as $P<0.05$.

\section{RESULTS}

\section{Total acidity, $\mathrm{pH}$, and organic acids contents}

The total acidity, $\mathrm{pH}$, and organic acids contents of kale/ apple juice and fermented beverage are shown in Table 1. The total acidity of kale/apple juice and fermented beverage were $0.20 \pm 0.01 \%$ and $0.45 \pm 0.02 \%$, respectively. The $\mathrm{pH}$ value of fermented beverage $(4.10 \pm 0.01)$ was

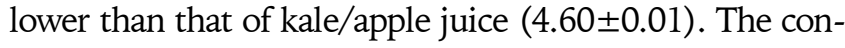
tents of formic acid, malic acid, and succinic acid in kale 
Table 1. Total acidity, $\mathrm{pH}$, and organic acids contents of kale/apple juice and the fermented beverage

\begin{tabular}{lcr}
\hline & Kale/apple juice & $\begin{array}{c}\text { Fermented } \\
\text { beverage }\end{array}$ \\
\hline Total acidity (\%) & $0.20 \pm 0.01$ & $0.45 \pm 0.02$ \\
$\mathrm{pH}$ & $4.60 \pm 0.01$ & $4.10 \pm 0.01$ \\
Organic acids $(\mu \mathrm{g} / \mathrm{mL})$ & $\mathrm{ND}$ & $2,355.5 \pm 2.4$ \\
$\quad$ Acetic acid & $137.1 \pm 0.3$ & $132.2 \pm 1.2$ \\
Formic acid & $851.2 \pm 43.9$ & $743.0 \pm 8.4$ \\
Malic acid & $1,042.7 \pm 12.2$ & $951.3 \pm 9.9$ \\
Succinic acid & & \\
\hline
\end{tabular}

Values are mean \pm SD.

ND: not detected.

/apple juice were $137.1 \pm 0.3 \mu \mathrm{g} / \mathrm{mL}, 851.2 \pm 43.9 \mu \mathrm{g} / \mathrm{mL}$, and $1,042.7 \pm 12.2 \mu \mathrm{g} / \mathrm{mL}$, respectively. The contents of acetic acid, formic acid, malic acid, and succinic acid in fermented beverage were $2,355.5 \pm 2.4 \mu \mathrm{g} / \mathrm{mL}, 132.2 \pm 1.2$ $\mu \mathrm{g} / \mathrm{mL}, 743.0 \pm 8.4 \mu \mathrm{g} / \mathrm{mL}$, and $951.3 \pm 9.9 \mu \mathrm{g} / \mathrm{mL}$, respectively. Among these organic acids, the content of acetic acid was the highest in fermented beverage. Hence, acetic acid was not detected in kale/apple juice.

\section{Total polyphenol and flavonoid contents}

The polyphenol and flavonoid contents of kale/apple juice and fermented beverage are shown in Table 2 . The polyphenol contents of kale/apple juice (44.0 $\pm 0.3 \mathrm{mg}$ TAE/ $100 \mathrm{~mL}$ ) and fermented beverage $(43.2 \pm 0.5 \mathrm{mg} \mathrm{TAE} / 100$ $\mathrm{mL}$ ) were not significantly different. Total flavonoid content of fermented beverage $(24.5 \pm 0.2 \mathrm{mg} \mathrm{QE} / 100 \mathrm{~mL})$ was significantly higher than that of kale/apple juice (19.7 $\pm 0.1 \mathrm{mg} \mathrm{QE} / 100 \mathrm{~mL}, P<0.01$ ).

\section{Inhibitory activities of $\alpha$-glucosidase and pancreatic lipase in vitro}

Kale/apple juice and fermented beverage inhibited yeast $\alpha$-glucosidase activities by $33.5 \pm 2.2 \%$ and $41.9 \pm 1.8 \%$, respectively, whereas acarbose, an $\alpha$-glucosidase inhibitor, inhibited $\alpha$-glucosidase activity by $65.9 \pm 3.8 \%$ (Fig. $1)$. The inhibitory activities of kale/apple juice and fermented beverage against pancreatic lipase were $45.0 \pm$ $2.1 \%$ and $54.5 \pm 2.9 \%$, respectively. Orlistat, a pancreatic lipase inhibitor, inhibited the enzyme activity by $89.7 \pm$

Table 2. Total polyphenol and flavonoid contents of kale/apple juice and the fermented beverage

\begin{tabular}{lcl}
\hline & $\begin{array}{c}\text { Kale/apple } \\
\text { juice }\end{array}$ & $\begin{array}{c}\text { Fermented } \\
\text { beverage }\end{array}$ \\
\hline Total polyphenol (mg TAE/100 mL) & $44.0 \pm 0.3$ & $43.2 \pm 0.5^{\mathrm{ns}}$ \\
Total flavonoid (mg QE/100 mL) & $19.7 \pm 0.1$ & $24.5 \pm 0.2^{*}$ \\
\hline
\end{tabular}

Values are mean \pm SD.

ns: not significant.

*Significantly different at $P<0.01$

$\mathrm{TAE}$, tannic acid equivalents; $\mathrm{QE}$, quercetin equivalents.

\section{7\% (Fig. 2).}

\section{Characteristics of the subjects}

All 24 subjects completed the study without experiencing any adverse effects. The anthropometric and biochemical characteristics of the subjects at pre- and post-treatment are shown in Table 3. All subjects were diagnosed with metabolic syndrome based on the NCEP-ATP III criteria. Body weight, BMI, body fat content, waist circumference, and blood pressure did not significantly differ between treatment groups at baseline. Intake of energy and major nutrients were similar between treatment groups at baseline and after the 10 weeks of treatment. After the treatment period, mean daily energy intake of the control and fermented beverage groups were 2,478 \pm 423 and 2,564 \pm $371 \mathrm{kcal}$, respectively (data not shown). Body weight, BMI, body fat content, waist circumference, and SBP and DBP were not significantly affected by consumption of fermented beverage. Moreover, consumption of fermented

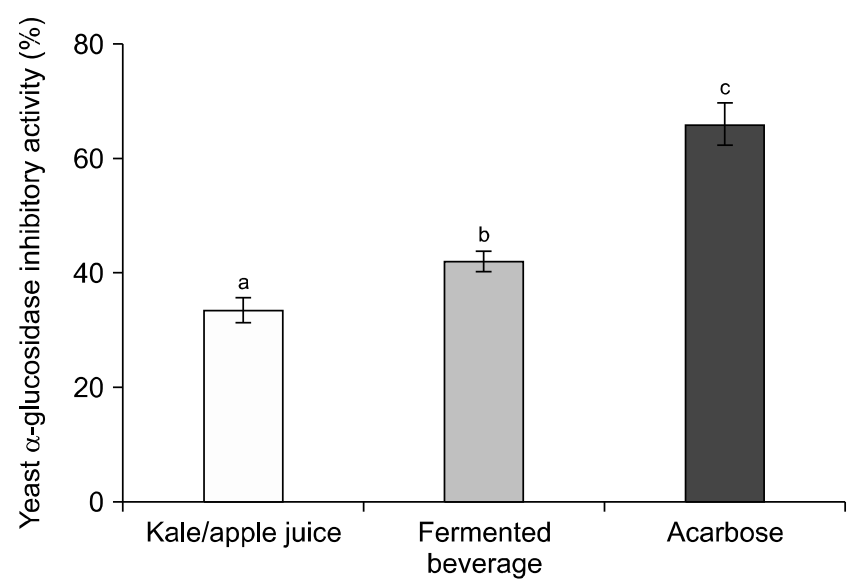

Fig. 1. Inhibitory activities of kale/apple juice and fermented beverage against yeast $\alpha$-glucosidase. Values represent mean \pm $\mathrm{SD}$ of triplicate measurements. Each bar with different letters $(\mathrm{a}-\mathrm{c})$ is significantly different at $P<0.01$.

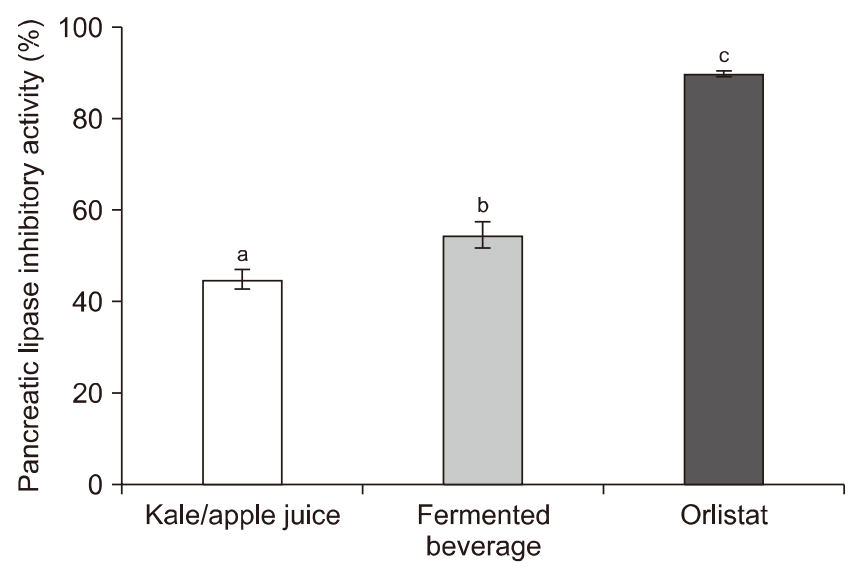

Fig. 2. Inhibitory activities of kale/apple juice and fermented beverage against pancreatic lipase. Values represent mean \pm SD of triplicate measurements. Each bar with different letters $(a-c)$ is significantly different at $P<0.01$. 
Table 3. Anthropometric and biochemical characteristics of subjects

\begin{tabular}{|c|c|c|c|c|c|c|}
\hline \multirow{2}{*}{ Group ${ }^{1)}$} & \multicolumn{3}{|c|}{ Control $(n=12)$} & \multicolumn{3}{|c|}{ Fermented beverage $(n=12)$} \\
\hline & Pre-treatment & Post-treatment & Difference ${ }^{2)}$ & Pre-treatment & Post-treatment & Difference \\
\hline Age (y) & & $40.2 \pm 9.2$ & & & $42.6 \pm 9.0$ & \\
\hline Body weight (kg) & $81.8 \pm 25.6$ & $82.8 \pm 24.8$ & $1.0 \pm 2.0^{\mathrm{ns}}$ & $79.4 \pm 8.8$ & $80.2 \pm 8.6$ & $0.7 \pm 1.6^{\mathrm{ns}}$ \\
\hline BMI $\left(\mathrm{kg} / \mathrm{m}^{2}\right)^{3)}$ & $27.6 \pm 7.5$ & $27.9 \pm 7.2$ & $0.4 \pm 0.7^{\mathrm{ns}}$ & $26.1 \pm 2.3$ & $26.4 \pm 2.3$ & $0.3 \pm 0.5^{\mathrm{ns}}$ \\
\hline Body fat (\%) & $28.2 \pm 6.4$ & $28.5 \pm 5.9$ & $0.3 \pm 1.7^{\mathrm{ns}}$ & $24.9 \pm 2.7$ & $25.8 \pm 3.2$ & $0.8 \pm 1.8^{\mathrm{ns}}$ \\
\hline Waist circumference $(\mathrm{cm})$ & $95.1 \pm 18.2$ & $95.3 \pm 17.3$ & $0.2 \pm 4.2^{\mathrm{ns}}$ & $92.8 \pm 5.6$ & $93.2 \pm 6.2$ & $0.5 \pm 2.4^{\mathrm{ns}}$ \\
\hline SBP $(\mathrm{mmHg})$ & $142.1 \pm 23.4$ & $141.0 \pm 19.7$ & $-1.1 \pm 13.1^{\mathrm{ns}}$ & $135.5 \pm 12.6$ & $135.9 \pm 9.8$ & $0.4 \pm 7.1^{\mathrm{ns}}$ \\
\hline $\mathrm{DBP}(\mathrm{mmHg})$ & $89.3 \pm 15.6$ & $90.1 \pm 10.7$ & $0.8 \pm 9.7^{\mathrm{ns}}$ & $85.8 \pm 9.8$ & $87.0 \pm 10.4$ & $1.3 \pm 7.5^{\mathrm{ns}}$ \\
\hline $\operatorname{ALT}(U / L)$ & $27.8 \pm 18.8$ & $26.2 \pm 16.0$ & $-1.7 \pm 5.3^{\mathrm{ns}}$ & $26.7 \pm 9.1$ & $28.5 \pm 13.3$ & $1.8 \pm 6.9^{\mathrm{ns}}$ \\
\hline AST (U/L) & $27.7 \pm 16.4$ & $26.3 \pm 14.7$ & $-1.3 \pm 6.3^{\text {ns }}$ & $27.8 \pm 6.0$ & $30.5 \pm 6.8$ & $2.7 \pm 9.2^{\mathrm{ns}}$ \\
\hline
\end{tabular}

${ }^{11}$ The fermented beverage and control groups received $250 \mathrm{~mL}$ of fermented beverage and water containing fructose, glucose, and sucrose twice a day for 10 weeks, respectively.

${ }^{2)}$ Differences between pre- and post-treatment values within each group.

${ }^{3)}$ BMI (body mass index) = body weight $(\mathrm{kg}) /$ height $(\mathrm{m})^{2}$

Values are mean \pm SD.

SBP, systolic blood pressure; DBP, diastolic blood pressure; ALT, alanine aminotransferase; AST, aspartate aminotransferase.

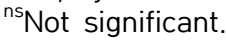

Table 4. Plasma glucose, insulin, and homeostasis model assessment for insulin resistance (HOMA-IR) values of subjects

\begin{tabular}{lcccccccc}
\hline \multirow{2}{*}{ Group } & \multicolumn{3}{c}{ Control $(\mathrm{n}=12)$} & & \multicolumn{3}{c}{ Fermented beverage $(\mathrm{n}=12)$} \\
\cline { 2 - 3 } & Pre-treatment & Post-treatment & Difference ${ }^{2)}$ & & Pre-treatment & Post-treatment & Difference \\
\hline Glucose $(\mathrm{mg} / \mathrm{dL})$ & $92.2 \pm 17.3$ & $95.1 \pm 16.0$ & $2.9 \pm 6.6^{\text {ns }}$ & & $95.2 \pm 20.1$ & $91.7 \pm 14.0$ & $-3.5 \pm 9.9^{\text {ns }}$ \\
Insulin $(\mu \mathrm{U} / \mathrm{mL})$ & $8.6 \pm 4.3$ & $9.0 \pm 4.3$ & $0.5 \pm 1.9^{\text {ns }}$ & & $8.9 \pm 2.6$ & $7.8 \pm 3.5$ & $-1.1 \pm 2.0^{\text {ns }}$ \\
HOMA-IR $^{3)}$ & $1.9 \pm 0.9$ & $2.1 \pm 0.8$ & $0.2 \pm 0.5^{\text {ns }}$ & & $2.1 \pm 0.6$ & $1.7 \pm 0.7$ & $-0.3 \pm 0.5^{*}$ \\
\hline
\end{tabular}

${ }^{11}$ The fermented beverage and control groups received $250 \mathrm{~mL}$ of fermented beverage and water containing fructose, glucose, and sucrose twice a day for 10 weeks, respectively.

${ }^{2}$ Differences between the pre- and post-treatment values within each group.

${ }^{3)}$ Homeostasis model assessment for insulin resistance $(\mathrm{HOMA}-\mathrm{IR})=$ fasting glucose $(\mathrm{mmol} / \mathrm{L}) \times$ fasting insulin $(\mu \mathrm{U} / \mathrm{mL}) / 22.5$.

Values are mean \pm SD.

${ }^{*}$ Pre- and post-treatment values are significantly different at $P<0.05$.

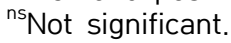

beverage did not alter plasma ALT and AST activities during the test period.

\section{Effects of fermented beverage on glycemic control}

The effects of fermented beverage on glycemic control are shown in Table 4. Plasma glucose and insulin levels in the control and fermented beverage groups did not significantly differ at baseline and post-treatment. After consumption of the fermented beverage for 10 weeks, HOMA-IR value, an index of insulin resistance, was significantly reduced $(P<0.05)$ compared with baseline $(2.1$ \pm 0.6 vs $1.7 \pm 0.7)$. However, HOMA-IR values of the control group did not significantly differ between baseline $(1.9 \pm 0.9)$ and post-treatment $(2.1 \pm 0.8)$.

\section{Effects of fermented beverage on lipid profiles}

The plasma lipid profiles in the control and fermented beverage groups are shown in Table 5. After 10 weeks of fermented beverage consumption, plasma triglyceride levels were significantly reduced compared with baseline (202.6 \pm 88.1 vs $193.0 \pm 90.7 \mathrm{mg} / \mathrm{dL}, P<0.05)$. Treatment of fermented beverage also significantly decreased atherogenic index compared with baseline $(6.7 \pm 4.1$ vs $6.0 \pm$ 4.1, $P<0.05)$. Plasma triglyceride levels and atherogenic index of the control group did not significantly differ between baseline $(184.7 \pm 83.7 \mathrm{mg} / \mathrm{dL}$ and $4.8 \pm 2.0$, respectively) and post-treatment $(189.4 \pm 73.5 \mathrm{mg} / \mathrm{dL}$ and $5.2 \pm$ 1.8, respectively). Plasma cholesterol, LDL-cholesterol, and HDL-cholesterol levels were not significantly affected by consumption of the fermented beverage.

\section{Effects of fermented beverage on antioxidant and anti- inflammatory status}

The antioxidant and anti-inflammatory effects in the control and fermented beverage groups are shown Table 6 . After consumption of the fermented beverage for 10 weeks, plasma TBARS levels were significantly decreased compared with baseline $(1.7 \pm 0.5$ vs $1.5 \pm 0.7 \mathrm{nmol} / \mathrm{mL}$, $P<0.05)$. Plasma TBARS levels of the control group did not significantly differ between baseline $(1.9 \pm 0.7 \mathrm{nmol} /$ $\mathrm{mL})$ and post-treatment $(2.1 \pm 0.8 \mathrm{nmol} / \mathrm{mL})$. Plasma GSH levels and the activities of superoxide dismutase 
Table 5. Plasma lipid profiles and atherogenic index of subjects

\begin{tabular}{|c|c|c|c|c|c|c|}
\hline \multirow{2}{*}{ Group ${ }^{1)}$} & \multicolumn{3}{|c|}{ Control $(n=12)$} & \multicolumn{3}{|c|}{ Fermented beverage $(n=12)$} \\
\hline & Pre-treatment & Post-treatment & Difference ${ }^{2)}$ & Pre-treatment & Post-treatment & Difference \\
\hline Triglyceride (mg/dL) & $184.7 \pm 83.7$ & $189.4 \pm 73.5$ & $4.6 \pm 17.5^{\mathrm{ns}}$ & $202.6 \pm 88.1$ & $193.0 \pm 90.7$ & $-9.6 \pm 14.2^{*}$ \\
\hline Cholesterol (mg/dL) & $193.2 \pm 33.0$ & $187.6 \pm 40.7$ & $-5.6 \pm 14.1^{\mathrm{ns}}$ & $198.0 \pm 35.7$ & $196.2 \pm 37.1$ & $-1.9 \pm 17.5^{\mathrm{ns}}$ \\
\hline HDL-cholesterol (mg/dL) & $38.8 \pm 6.9$ & $37.0 \pm 7.8$ & $-1.8 \pm 4.2^{\mathrm{ns}}$ & $33.5 \pm 9.0$ & $35.0 \pm 6.4$ & $1.5 \pm 4.9^{\mathrm{ns}}$ \\
\hline LDL-cholesterol (mg/dL) & $111.7 \pm 33.6$ & $110.6 \pm 32.9$ & $-1.1 \pm 8.4^{\mathrm{ns}}$ & $120.6 \pm 38.4$ & $118.4 \pm 31.3$ & $-2.3 \pm 11.8^{\text {ns }}$ \\
\hline Atherogenic index ${ }^{3)}$ & $4.8 \pm 2.0$ & $5.2 \pm 1.8$ & $0.4 \pm 1.0^{\mathrm{ns}}$ & $6.7 \pm 4.1$ & $6.0 \pm 4.1$ & $-0.7 \pm 1.0^{*}$ \\
\hline
\end{tabular}

${ }^{11}$ The fermented beverage and control groups received $250 \mathrm{~mL}$ of fermented beverage and water containing fructose, glucose, and sucrose twice a day for 10 weeks, respectively.

${ }^{2)}$ Differences between the pre- and post-treatment values within each group.

${ }^{3)}$ Atherogenic index = triglyceride/HDL-cholesterol.

Values are mean \pm SD.

${ }^{*}$ Pre- and post-treatment values are significantly different at $P<0.05$.

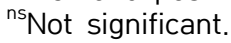

Table 6. Plasma antioxidant activities and inflammatory cytokine levels of subjects

\begin{tabular}{|c|c|c|c|c|c|c|}
\hline \multirow[b]{2}{*}{ Group ${ }^{1)}$} & \multicolumn{3}{|c|}{ Control $(n=12)$} & \multicolumn{3}{|c|}{ Fermented beverage $(n=12)$} \\
\hline & $\begin{array}{l}\text { Pre- } \\
\text { treatment }\end{array}$ & $\begin{array}{c}\text { Post- } \\
\text { treatment }\end{array}$ & Difference $^{2)}$ & $\begin{array}{c}\text { Pre- } \\
\text { treatment }\end{array}$ & $\begin{array}{c}\text { Post- } \\
\text { treatment }\end{array}$ & Difference \\
\hline TBARS (nmol/mL) & $1.9 \pm 0.7$ & $2.1 \pm 0.8$ & $0.2 \pm 0.5^{\mathrm{ns}}$ & $1.7 \pm 0.5$ & $1.5 \pm 0.7$ & $-0.3 \pm 0.5^{*}$ \\
\hline Glutathione $(\mu \mathrm{mol} / \mathrm{L})$ & $2.3 \pm 0.4$ & $2.5 \pm 0.4$ & $0.2 \pm 0.6^{\mathrm{ns}}$ & $2.5 \pm 0.5$ & $2.7 \pm 0.5$ & $0.2 \pm 0.3^{\text {ns }}$ \\
\hline Superoxide dismutase (U/g protein) & $1.2 \pm 0.4$ & $1.1 \pm 0.4$ & $-0.1 \pm 0.5^{\mathrm{ns}}$ & $1.0 \pm 0.2$ & $1.1 \pm 0.3$ & $0.1 \pm 0.4^{\mathrm{ns}}$ \\
\hline Catalase (U/mg protein) & $193.2 \pm 29.1$ & $201.7 \pm 31.3$ & $8.1 \pm 26.7^{\mathrm{ns}}$ & $197.3 \pm 26.0$ & $209.4 \pm 28.9$ & $12.7 \pm 19.1^{\text {ns }}$ \\
\hline Glutathione peroxidase ( $\mathrm{U} / \mathrm{mg}$ protein) & $33.9 \pm 4.8$ & $31.8 \pm 5.7$ & $-2.1 \pm 7.6^{\mathrm{ns}}$ & $31.3 \pm 4.3$ & $29.4 \pm 8.1$ & $-1.9 \pm 9.9^{\text {ns }}$ \\
\hline Adiponectin $(\mu \mathrm{g} / \mathrm{mL})$ & $9.4 \pm 2.9$ & $9.9 \pm 2.6$ & $0.5 \pm 2.9^{\text {ns }}$ & $8.6 \pm 2.7$ & $9.2 \pm 4.0$ & $0.6 \pm 4.4^{\mathrm{ns}}$ \\
\hline TNF- $\alpha(p g / m L)$ & $12.5 \pm 2.9$ & $13.3 \pm 3.6$ & $0.8 \pm 2.4^{\mathrm{ns}}$ & $13.3 \pm 3.2$ & $11.2 \pm 2.0$ & $-2.2 \pm 2.8^{*}$ \\
\hline hs-CRP (mg/L) & $2.7 \pm 2.6$ & $3.1 \pm 2.4$ & $0.3 \pm 1.3^{\mathrm{ns}}$ & $2.2 \pm 2.6$ & $1.4 \pm 2.1$ & $-0.8 \pm 1.1^{*}$ \\
\hline
\end{tabular}

${ }^{11}$ The fermented beverage and control groups received $250 \mathrm{~mL}$ of fermented beverage and water containing fructose, glucose, and sucrose twice a day for 10 weeks, respectively.

${ }^{2)}$ Differences between the pre- and post-treatment values within each group.

Values are mean \pm SD.

${ }^{*}$ Pre- and post-treatment values are significantly different at $P<0.05$.

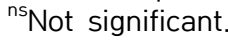

(SOD), catalase, and glutathione peroxide (GPx) were not significantly affected by the consumption of fermented beverage treatment. Consumption of the fermented beverage significantly decreased $(P<0.05)$ plasma TNF- $\alpha$ $(11.2 \pm 2.0 \mathrm{pg} / \mathrm{mL})$ and hs-CRP $(1.4 \pm 2.1 \mathrm{mg} / \mathrm{L})$ levels compared with baseline $(13.3 \pm 3.2 \mathrm{pg} / \mathrm{mL}$ and $2.2 \pm 2.6$ $\mathrm{mg} / \mathrm{L}$, respectively). Plasma TNF- $\alpha$ and hs-CRP levels did not significantly differ baseline $(12.5 \pm 2.9 \mathrm{pg} / \mathrm{mL}$ and 2.7 $\pm 2.6 \mathrm{mg} / \mathrm{L})$ and post-treatment $(13.3 \pm 3.6 \mathrm{pg} / \mathrm{mL}$ and $3.1 \pm 2.4 \mathrm{mg} / \mathrm{L}$ ) in the control group. Plasma adiponectin levels were not significantly affected by the consumption of fermented beverage.

\section{DISCUSSION}

Metabolic syndrome refers to a cluster of metabolic abnormalities, including abdominal obesity, hyperglycemia, dyslipidemia, and hypertension, and is a major risk factor for type 2 diabetes mellitus and CVD (Dragsbæk et al., 2016). Insulin resistance is strongly associated with obe- sity and other components of metabolic syndrome (Bagry et al., 2008). Stern et al. (2004) reported the association between insulin resistance and metabolic syndrome. Thus, the control of insulin resistance is important to prevent development of metabolic syndrome.

Consumption of the fermented beverage did not alter plasma ALT and AST activities during the treatment period, suggesting that consumption of the fermented beverage is safe. Previous studies did not report any adverse effects following intake of $90 \mathrm{~mL}$ vinegar containing $4,500 \mathrm{mg}$ of acetic acid for 4 weeks in healthy subjects (Kondo et al., 2009).

In the present study, plasma glucose and insulin levels in the fermented beverage group tended to decrease relative to the control group, although these differences were not significant. It is possible that the fermented beverage may not contain enough acetic acid to improve glycemic control. Subjects consumed $500 \mathrm{~mL}$ of fermented beverage per day, which contains $1,180 \mathrm{mg}$ of acetic acid. A previous study showed that consumption of $1,400 \mathrm{mg}$ of acetic acid twice daily for 12 weeks improves glycemic 
control in well-controlled type 2 diabetic patients (Johnston et al., 2009). In addition, Ostman et al. (2005) found that acetic acid at doses of $\geq 1,400 \mathrm{mg}$ decreases glucose and insulin responses in healthy subjects, which is indicative of a dose-response relationship. Although consumption of 1,400 mg of acetic acid improved glycemic control, consumption of lower doses did not affect glycemic control in well-controlled type 2 diabetic patients (Johnston et al., 2009). However, in the present study, consumption of the fermented beverage significantly reduced HOMA-IR values, an index of insulin resistance. The improvement of insulin sensitivity was modest by consumption of vinegar containing $750 \mathrm{mg}$ of acetic acid in women with polycystic ovary syndrome (Ogawa et al., 2000). Vinegar may alleviate insulin resistance via suppressing digestive enzymes. Johnston et al. (2009) demonstrated that consumption of vinegar before a high-carbohydrate meal improves postprandial glucose and insulin levels in insulin-resistant subjects. $\alpha$-Glucosidase is the key enzyme to digest for dietary carbohydrates, and inhibition of $\alpha$-glucosidase could be effective in altering glucose absorption by delaying digestion of dietary carbohydrates (Watanabe et al., 1997). We showed that the kale/apple juice and fermented beverage inhibited $\alpha$-glucosidase activities in vitro. Furthermore, the fermented beverage exhibited 1.3-fold stronger $\alpha$-glucosidase inhibitory activity than kale/apple juice in vitro. Vinegar contains approximately $4 \sim 20 \%$ acetic acid, the main ingredient of vinegar (Samad et al., 2016). Treatment with acetic acid at $5 \mathrm{mmol} / \mathrm{L}$ for 15 days decreased the activities of maltase and sucrase in Caco-2 cells (Ogawa et al., 2000). It has been reported that acetic acid could improve insulin resistance due to its inhibitory effects on digestive enzymes. Insulin resistance is an important initiating pathogenic mechanism of type 2 diabetes. Therefore, fermented beverages may be beneficial for preventing type 2 diabetes via improving insulin resistance.

In this study, plasma triglyceride levels significantly decreased following consumption of the fermented beverage, which contained bioactive compounds and organic acids. The hypotriglyceridemic effects of the fermented beverage may have been partly mediated by flavonoids. Several studies have shown that flavonoid could be beneficial for improving dyslipidemia. Kale and apple are good sources of flavonoids that improve serum lipid metabolism (Sato et al., 2016). In a previous study, kale decreased plasma triglyceride levels in subjects with baseline serum triglycerides levels of 150 199 mg/dL (Sato et al., 2016). Consumption of apple juice reduced serum triglyceride levels in high cholesterolemic rabbits (Setorki et al., 2009). Our results showed that the flavonoid content of the fermented beverage was higher than that of the kale/apple juice. These data suggested that the fermented beverage could be more effective in decreasing plasma triglyceride levels than kale/apple juice without vinegar. Vinegar and acetic acid improved lipid metabolism in human and animal studies (Kondo et al., 2009; Ok et al., 2013). Consumption of a beverage containing 750 or $1,500 \mathrm{mg}$ of acetic acid for 12 weeks decreased serum triglyceride levels in obese Japanese subjects (Kondo et al., 2009). Ok et al. (2013) reported that supplementation of acetic acid and pomegranate vinegar reduced plasma and hepatic triglyceride levels in obese rats. Halima et al. (2016) demonstrated that the acetic acid reduced serum triglyceride levels by reducing hepatic triglyceride storage, possibly via inhibition of lipogenesis in the liver and enhancement of fatty acid oxidation.

In our study, we showed that the inhibitory activity of the fermented beverage against pancreatic lipases was 1.2-fold stronger than that of kale/apple juice in vitro. Lipase inhibitors prevent hydrolysis of dietary fat in the small intestine, which reduces intestinal absorption of dietary fat and enhances fat excretion in feces. In a previous study, apple cider vinegar decreased intestine lipase activity and plasma total cholesterol and triglyceride levels in diabetic rats (Halima et al., 2016). The vinegar could prolong absorption of triglycerides by inhibiting lipase, and, subsequently, decrease plasma lipid concentration. It was reported the inhibitory activity of pancreatic lipase increased during vinegar fermentation of Elaeagnus multiflora fruit (Cho et al., 2017). Kim et al. (2018) reported that the inhibitory activity of pancreatic lipase in carrot vinegar is higher than that of carrot juice. Insulin resistance is associated with dyslipidemia characterized by hypertriglyceridemia and low HDL-cholesterol levels. Insulin resistance may lead to increase synthesis and secretion of very low-density lipoprotein, resulting in increased plasma triglyceride levels and decreased plasma HDL-cholesterol levels. Treatment of dyslipidemia is important to reduce risk of CVD in the insulin resistant state (Rader, 2007). The results of this study showed that the fermented beverage effectively ameliorated hypertriglyceridemia in subjects with metabolic syndrome. Thus, improving insulin resistance by consuming fermented beverage could contribute to lowering plasma triglyceride levels.

Insulin resistance may accelerate oxidative stress by overproducing reactive oxygen species (ROS) and attenuating antioxidant systems (Tangvarasittichai, 2015). Oxidative stress may be induced by decreases in antioxidant enzyme activities and increases in lipid peroxidation levels in subjects with metabolic syndrome (Palmieri et al., 2006; Armutcu et al., 2008). Several studies have reported that vinegar decreased lipid peroxidation levels and increased antioxidant enzyme activities (Bouazza et al., 2016; Halima et al., 2018). Pomegranate vinegar decreased serum and hepatic lipid peroxidation levels and increased serum SOD, GPx, and total antioxidant status 
in hyperlipidemic rats (Bouazza et al., 2016). Apple cider vinegar also attenuated oxidative stress by decreasing hepatic and renal lipid peroxidation, and increasing the activities of antioxidant enzyme in rats fed a high-fat diet (Halima et al., 2018). It was suggested that antioxidant effects of vinegar could be due to the high levels of flavonoids and acetic acid in vinegar (Halima et al., 2018). Banjarnahor and Artanti (2014) demonstrated that flavonoids could act as antioxidants by scavenging free radicals, suppressing enzymes associated with ROS generation, and enhancing internal antioxidant enzymes. It was suggested the flavonoids in fermented beverage are strong antioxidants that can scavenge free radicals, inhibit production of free radicals, and promote generation of antioxidant enzymes.

Insulin resistance is associated with low-grade inflammation and oxidative stress. CRP and TNF- $\alpha$, markers of inflammation, were elevated in subjects with insulin resistance. Insulin resistance causes the up-regulation of inflammatory adipokines, including CRP and TNF- $\alpha$, whereas decreases cytokines (Avramoglu et al., 2006; Bagry et al., 2008). Therefore, fermented beverages may contribute to improved antioxidant status and inflammation by decreasing lipid peroxidation and inflammatory adipokine levels.

The results of our study suggest that the fermented beverage, kale/apple juice containing $5 \%$ vinegar, may be effective in controlling metabolic syndrome by inhibiting $\alpha$-glucosidase and pancreatic lipase activities in vitro. Consumption of the fermented beverage for 10 weeks significantly decreased plasma triglyceride level, atherogenic index, and HOMA-IR value compared with baseline in subjects with metabolic syndrome $(P<0.05)$. In addition, plasma, TBARS, TNF- $\alpha$, and hs-CRP levels were significantly reduced $(P<0.05)$ following consumption of fermented beverage. Thus, the fermented beverage could be effective in improving metabolic syndrome in subjects with metabolic syndrome.

\section{ACKNOWLEDGEMENTS}

This work was supported by Korea Institute of Planning and Evaluation for Technology in Food, Agriculture, Forestry (IPET) through High Value-added Food Technology Development Program, funded by Ministry of Agriculture, Food and Rural Affairs (MAFRA) (116003-2).

\section{AUTHOR DISCLOSURE STATEMENT}

The authors declare no conflict of interest.

\section{REFERENCES}

Abbasian M, Delvarianzadeh M, Ebrahimi H, Khosravi F, Nourozi P. Relationship between serum levels of oxidative stress and metabolic syndrome components. Diabetes Metab Syndr. 2018. 12:497-500.

Ando K, Fujita T. Metabolic syndrome and oxidative stress. Free Radic Biol Med. 2009. 47:213-218.

Arai I, Amagaya S, Komatsu Y, Okada M, Hayashi T, Kasai M, et al. Improving effects of the extracts from Eugenia uniflora on hyperglycemia and hypertriglyceridemia in mice. J Ethnopharmacol. 1999. 68:307-314.

Armutcu F, Ataymen M, Atmaca H, Gurel A. Oxidative stress markers, C-reactive protein and heat shock protein 70 levels in subjects with metabolic syndrome. Clin Chem Lab Med. 2008. 46:785-790.

Avramoglu RK, Basciano H, Adeli K. Lipid and lipoprotein dysregulation in insulin resistant states. Clin Chim Acta. 2006. 368:1-19.

Bagry HS, Raghavendran S, Carli F. Metabolic syndrome and insulin resistance: perioperative considerations. Anesthesiology. 2008. 108:506-523.

Banjarnahor SDS, Artanti N. Antioxidant properties of flavonoids. Med J Indones. 2014. 23:239-244.

Bouazza A, Bitam A, Amiali M, Bounihi A, Yargui L, Koceir EA. Effect of fruit vinegars on liver damage and oxidative stress in high-fat-fed rats. Pharm Biol. 2016. 54:260-265.

Cho KM, Hwang CE, Joo OS. Change of physicochemical properties, phytochemical contents and biological activities during the vinegar fermentation of Elaeagnus multiflora fruit. Korean J Food Preserv. 2017. 24:125-133.

Dragsbæk K, Neergaard JS, Laursen JM, Hansen HB, Christiansen $\mathrm{C}$, Beck-Nielsen H, et al. Metabolic syndrome and subsequent risk of type 2 diabetes and cardiovascular disease in elderly women: challenging the current definition. Medicine. 2016. 95:e4806. https://doi.org/10.1097/MD.0000000000004806

Ellman GL. Tissue sulfhydryl groups. Arch Biochem Biophys. 1959. 82:70-77.

Folin O, Denis W. On phosphotungstic-phosphomolybdic compounds as color reagents. J Biol Chem. 1912. 12:239-243.

Halima BH, Sarra K, Houda BJ, Sonia G, Abdallah A. Antihyperglycemic, antihyperlipidemic and modulatory effects of apple cider vinegar on digestive enzymes in experimental diabetic rats. Int J Pharmacol. 2016. 12:505-513.

Halima BH, Sonia G, Sarra K, Houda BJ, Fethi BS, Abdallah A. Apple cider vinegar attenuates oxidative stress and reduces the risk of obesity in high-fat-fed male wistar rats. J Med Food. 2018. 21:70-80.

Johnston CS, White AM, Kent SM. Preliminary evidence that regular vinegar ingestion favorably influences hemoglobin $A_{1} C$ values in individuals with type 2 diabetes mellitus. Diabetes Res Clin Pract. 2009. 84:e15-e17.

Kim JI, Han DW, Yun JA, Baek HJ, Lim SW. Pancreatic lipase inhibitory activity and antioxidant activity of carrot vinegar. Korean Soc Biotechnol Bioeng J. 2018. 33:104-109.

Kondo T, Kishi M, Fushimi T, Ugajin S, Kaga T. Vinegar intake reduces body weight, body fat mass, and serum triglyceride levels in obese Japanese subjects. Biosci Biotechnol Biochem. 2009. 73:1837-1843.

Mottillo S, Filion KB, Genest J, Joseph L, Pilote L, Poirier P, et al. The metabolic syndrome and cardiovascular risk a systematic review and meta-analysis. J Am Coll Cardiol. 2010. 56:11131132.

National Cholesterol Education Program (NCEP) Expert Panel on Detection, Evaluation, and Treatment of High Blood Cholesterol in Adults (Adult Treatment Panel III). Third report of the National Cholesterol Education Program (NCEP) Expert 
Panel on Detection, Evaluation, and Treatment of High Blood Cholesterol in Adults (Adult Treatment Panel III) final report. Circulation. 2002. 106:3143-3421.

Ogawa N, Satsu H, Watanabe H, Fukaya M, Tsukamoto Y, Miyamoto $\mathrm{Y}$, et al. Acetic acid suppresses the increase in disaccharidase activity that occurs during culture of Caco-2 cells. J Nutr. 2000. 130:507-513.

Ohkawa H, Ohishi N, Yagi K. Assay for lipid peroxides in animal tissues by thiobarbituric acid reaction. Anal Biochem. 1979. 95:351-358.

Ok E, Do GM, Lim Y, Park JE, Park YJ, Kwon O. Pomegranate vinegar attenuates adiposity in obese rats through coordinated control of AMPK signaling in the liver and adipose tissue. Lipids Health Dis. 2013. 12:163. https://doi.org/10.1186/1476511X-12-163

Ostman E, Granfeldt Y, Persson L, Björck I. Vinegar supplementation lowers glucose and insulin responses and increases satiety after a bread meal in healthy subjects. Eur J Clin Nutr. 2005. 59:983-988.

Palmieri VO, Grattagliano I, Portincasa P, Palasciano G. Systemic oxidative alterations are associated with visceral adiposity and liver steatosis in patients with metabolic syndrome. J Nutr. 2006. 136:3022-3026.

Petsiou EI, Mitrou PI, Raptis SA, Dimitriadis GD. Effect and mechanisms of action of vinegar on glucose metabolism, lipid profile, and body weight. Nutr Rev. 2014. 72:651-661.

Rader DJ. Effect of insulin resistance, dyslipidemia, and intra-abdominal adiposity on the development of cardiovascular disease and diabetes mellitus. Am J Med. 2007. 120:S12-S18.

Samad A, Azlan A, Ismail A. Therapeutic effects of vinegar: a review. Curr Opin Food Sci. 2016. 8:56-61.

Santos HO, de Moraes WMAM, da Silva GAR, Prestes J, Schoenfeld BJ. Vinegar (acetic acid) intake on glucose metabolism: a narrative review. Clin Nutr ESPEN. 2019. 32:1-7.

Sato N, Suzuki A, Kurokawa M, Hasumi K. Hypotriglyceridemic effect of kale - a randomized, double-blind, parallel-group, placebo-controlled study. Jpn Phrmacol Ther. 2016. 44:13371346.

Setorki M, Asgary S, Eidi A, Rohani AH, Esmaeil N. Effects of apple juice on risk factors of lipid profile, inflammation and coagulation, endothelial markers and atherosclerotic lesions in high cholesterolemic rabbits. Lipids Health Dis. 2009. 8:39. https://doi.org/10.1186/1476-511X-8-39

Stern MP, Williams K, González-Villalpando C, Hunt KJ, Haffner $\mathrm{SM}$. Does the metabolic syndrome improve identification of individuals at risk of type 2 diabetes and/or cardiovascular disease?. Diabetes Care. 2004. 27:2676-2681.

Tangvarasittichai S. Oxidative stress, insulin resistance, dyslipidemia and type 2 diabetes mellitus. World J Diabetes. 2015. 6:456-480.

Watanabe J, Kawabata J, Kurihara H, Niki R. Isolation and identification of $\alpha$-glucosidase inhibitors from tochu-cha (Eucommia ulmoides). Biosci Biotechnol Biochem. 1997. 61:177-178.

Zhishen J, Mengcheng T, Jianming W. The determination of flavonoid contents in mulberry and their scavenging effects on superoxide radicals. Food Chem. 1999. 64:555-559. 